\title{
Game Performance Versus Competitive Performance in the World Championship of Handball 2011
}

\author{
by \\ Óscar Gutiérrez¹, José L. Ruiz²
}

This article assesses the game performance of the teams participating in the Men's World Championship of Handball of 2011 by using Data Envelopment Analysis (DEA) and the cross-efficiency evaluation. DEA uses Linear Programming to yield a measure of the overall performance of the game of particular teams, and allows us to identify relative strengths and weaknesses by means of benchmarking analysis. The cross-efficiency evaluation provides a peerappraisal of the teams with different patterns of game, and makes it possible to rank them. Comparisons between this ranking and the final classification in the championship provide an insight into the game performance of the teams versus their competitive performance. We highlight the fact that France, which is the world champion, is also identified as an "all-round" performer in our game performance assessment.

Key words: team game performance, Data Envelopment Analysis, cross-efficiency evaluation, handball.

\section{Introduction}

Tactics are considered an important aspect of team sports, which can be expressed individually or collectively. The collective strategic behaviour is often understood as the sum of individual behaviours, thus tactical decisions are sometimes evaluated individually as a way of evaluating collective tactics. The collective game in team sports is developed by taking into account the characteristics of the team's own players and the need to counteract the quality of the players of the opposing team. The achievement of high team performance depends on several factors such as technical skills, physical fitness or relationships between players. This is a complex system that is constantly changing and cannot be controlled by means of external fixed criteria, so regulatory mechanisms of dynamical systems can facilitate this task.

Tactical assessment can be made on the basis of either real matches or scrimmage games, with the purpose of evaluating specific aspects of tactical decisions of the players. Nevertheless, the assessment of tactics in real matches is very important, because there are situations that only arise in the context of real game and these would be difficult to reproduce in scrimmage conditions. Extensive literature deals with tactical performance evaluation in team sports based on tactical indexes. There are several articles that are intended to determine which indexes are more representative or which may be more significant for the analysis of tactics. See the investigations in football (Tenga et al., 2010a, 2010b, 2010c), basketball (Swalgin, 1998; Trninic and Dizdan, 2000; Trninic et al., 2000) and water polo (Hraste et al., 2008).

There are also some works focusing on different strategies, approaches and styles of the teams, which may lead to different tactical indexes. It is argued that the analysis of the different groups formed in the preliminary stages of the Handball World Championship 2003

1 - Center of Research in Sport, University Miguel Hernández of Elche, Spain.

2 - Center of Operations Research, University Miguel Hernández of Elche, Spain. 
generated different indicators of success taking into account the reference groups and the different characteristics of each team (Gruic et al., 2006). This suggests that we should not use a unique pre-established pattern of game that is imposed to all the teams in their assessments. Instead, we should use a model that somehow takes into consideration the characteristics of the game of each team. This is why we propose the use of "Data Envelopment Analysis" (DEA) (Charnes et al., 1978) for the assessment of team game performance.

To define a measure of the overall team performance in the game we must determine how the variables that describe the different aspects of the game have to be aggregated. In order to do so, we need to specify the importance (the weight) that is to be attached to each of these aspects of the game. Traditionally, teams are assessed on the basis of a common set of weights. However, in this traditional approach the choice itself of the weights often raises serious difficulties, and in many cases the analysts do not agree upon the weights to be used. In DEA there is no need to know such weights beforehand. The weights are determined trying to show the team under assessment in its best possible light. Besides, the DEA weights are team-specific, so this methodology provides a self-evaluation in which each team can exploit its strengths in the assessments. As another interesting feature of this methodology, we point out that with DEA we may develop plans for improvement of the game by means of benchmarking analysis. The teams are classified into efficient and inefficient, so the latter are assessed with respect to the former. DEA allows us to identify the weaknesses in the game of the inefficient teams and to set efficient targets, which represent levels of performance in each aspect of the game that would make each of them perform efficiently. Like the DEA weights, the targets are also team-specific. These targets result from the selection of a benchmark that is made taking into consideration the type of the game of the team under assessment. The key issue is that each team may have a different way to achieve the efficiency, which will obviously depend on the characteristics of its game. However, the main weakness of DEA is perhaps the fact that it cannot provide a ranking of teams based on the measures of efficiency it yields since, as said before, the score of each team is calculated with weights that are usually different from those of the others. For this reason, we also propose here the use of the cross-efficiency evaluation (Sexton et al., 1986; Doyle and Green, 1994), which is an extension of DEA aimed at providing a ranking. The idea behind the cross-efficiency evaluation is to assess each team with the DEA weights of all the teams instead of with only its own weights. This provides a peer-appraisal of the game performance of the teams with different patterns of game and, in addition, we can rank the teams according to the resulting cross-efficiency scores.

DEA has been successfully used in public and private sectors and, in particular, in the context of sports. For instance, Cooper et al. (2009) assess basketball players by using the statistics of the Spanish premier league. Cooper et al. (2011) provide a ranking of basketball players with a cross-efficiency evaluation. DEA and crossefficiency evaluation are combined for the assessment and ranking of professional tennis players (Ruiz et al., 2011). Ramón et al. (2012) also rank tennis players with a common set of weights obtained from DEA weights. See also the evaluations of players by using DEA in baseball (Anderson and Sharp, 1997; Chen and Johnson, 2010; Sexton and Lewis, 2003; Sueyoshi et al., 1999), golf (Fried et al., 2004; Fried and Tauer, 2011; Ueda and Amatatsu, 2009) and football (Alp, 2006).

DEA has been used not only for the assessment of players. See, for example, the case of soccer, where we can find evaluations of teams (Boscá et al., 2009; Espitia-Escuer and GarcíaCebrián, 2004; García-Sánchez, 2007; GonzálezGómez and Picazo-Tadeo, 2010; Haas, 2003; Haas et al., 2001), coaches (Dawson et al., 2000) and clubs (Barros et al., 2010). At the level of countries, DEA has been used for measuring the performance of the participating nations at the Summer Olympics Games (Lozano et al., 2002; Soares de Mello et al., 2009; Wu et al., 2010; Zhang et al., 2009).

Finally, we can also find applications of DEA analyzing the efficiency in sports from other perspectives. Fizel and D'Itri (1999) study the impact on organizational performance of practices like firing and hiring managers. Volz (2009) provides efficiency scores not only of team 
performance, but also of player salaries in Major League Baseball, and Einolf (2004) measures franchise payroll efficiency in the National Football League and Major League Baseball.

As far as we know, DEA and crossefficiency evaluation have not yet been used in handball. In this paper, we illustrate their use in an assessment of team game performance of the nations participating in the Men's World Championship in 2011 based on the statistics reported in that tournament. The comparisons of the results obtained with the final classification in the championship provide an insight into the game performance of the teams versus their competitive performance.

\section{Material and Methods}

\section{Participants}

The 24 teams that played in the Men's World Handball Championships of 2011 in Sweden were included.

\section{Measures}

The data in this article have been taken directly from the official statistics of the International Handball Federation (IHF) without elaboration by the authors. These are available in http://www.ihf.info/, and include all of the matches played during the Men's World Handball Championships of 2011 held in Sweden. Thus, we have a sample of 24 national teams which are described in terms of the following 8 variables: G6m (y1), Gwing (y2), G9m (y3), G7m (y4), Gfastb (y5) and Gbt ( $\left.\mathrm{y}_{6}\right)$ which are, respectively, the number of goals per game scored from $6 \mathrm{~m}$, from the wing position, those scored from $9 \mathrm{~m}$ and $7 \mathrm{~m}$ and the number of fastbreak and breakthrough goals, in all cases adjusted by the percentage of success; Rec ( $\left.\mathrm{y}_{7}\right)$ is the number of recoveries per game and Bloc (y8) is the number of blocks per game. These data provide information of each team regarding goals and shots from different distances, situations and positions, recoveries and blocks, and may thus reflect the effects of the tactical decisions concerning different aspects of the game like shooting, both in a positional attack and in transition, and defense. The 24 teams can be therefore described by means of the output vectors

$$
P_{j}=\left(y_{1, j}, \ldots, y_{8, j}\right)^{\prime}, j=1, \ldots, 24 .
$$

Analysis

We use the so-called CCR DEA model for the analysis of team efficiency. For a given team, say team 0 , the following linear problem provides the weights that allows us to aggregate the information regarding the 8 outputs above into a single value $\theta_{0}$

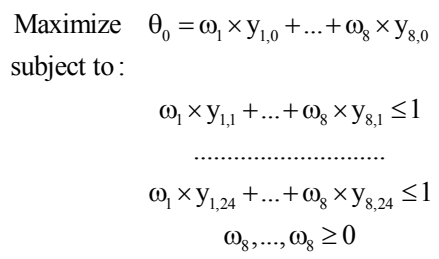

We can see that the objective in (1) is to find the weights $\omega$ 's that maximize the corresponding weighted sum of outputs for team 0 , subject to the condition that this weighted sum, calculated with these weights for the rest of teams, is in all cases lower than or equal to a given value, which is usually set at 1 . Thus, team 0 is said to be efficient if $\theta_{0}=1$. Otherwise, it is inefficient, and the lower $\theta_{0}$ the lesser its efficiency. Looking at model (1) we realize that in DEA there is no need to a priori know the weights that represent the importance to be attached to the different aspects of the game. When solving (1) each team has total freedom in the choice of such weights, which are determined trying to show it in its best possible light. This is of particular interest in the identification of inefficient teams: if a team is free to choose its own weights and others have a higher efficiency score with those weights, then a stronger statement is being made. However, this total weight flexibility may become an issue in the identification of efficient teams, since they sometimes take advantage of it and achieve the efficiency with weights that are inconsistent with the accepted views of experts. In particular, in DEA the units under assessment sometimes achieve the efficiency ignoring the variables with poor performance by attaching them a zero weight. To avoid this, it has been proposed in the literature to restrict the weights by incorporating into the analysis value judgements from experts regarding the relative importance of the variables (see chapter 4 in Cooper et al., 2011, for a recent survey on choices and uses of DEA weights). To be specific, in the analysis in the present paper we have imposed that the importance attached to the variables 
concerned with defense cannot be larger than that of those regarding the offensive aspects of the game.

By virtue of the duality theory in linear programming, DEA also provides a benchmarking analysis by solving the following model

$$
\begin{array}{cc}
\text { Maximize } & \phi_{0} \\
\text { subject to: } & \\
& \lambda_{1} \times \mathrm{P}_{1}+\ldots+\lambda_{24} \times \mathrm{P}_{24} \geq \phi_{0} \times \mathrm{P}_{0} \\
& \lambda_{1}+\ldots+\lambda_{24}=1 \\
& \lambda_{1}, \ldots, \lambda_{24} \geq 0
\end{array}
$$

The optimal value of (2), $\phi_{0}$, is actually the inverse of $\theta_{0}$ in (1). Therefore, team 0 is efficient if $\phi_{0}=1$, while it is rated as inefficient if $\phi_{0}>1$. Figure 1 illustrates graphically the idea behind model (2). Suppose that we have 3 handball teams that are to be assessed regarding two game factors, say, G6m and G9m. Their records in the championship in these two variables are $\mathrm{P}_{1}(2,7)$ for team $1, \mathrm{P}_{2}(10,3)$ for team 2 and $\mathrm{P}_{3}(4,3)$ for team 3 , i.e., team 1 , for example, scored $26 \mathrm{~m}$ goals per game and $79 \mathrm{~m}$ goals per game, and so on. The grey area is the so-called production possibility set (PPS), and includes the teams (real or virtual) that are assumed to be potential benchmarks in the assessments. Roughly speaking, in the PPS we have combinations of real teams, and others that represent worse performances. The points on the frontier of the PPS (the bold line) represent obviously "best practice" performances. Teams 1 and 2 are rated as efficient because we cannot find in the PPS other teams that score more $6 \mathrm{~m}$ goals and more $9 \mathrm{~m}$ goals than them. In that case, $\phi_{1}$ and $\phi_{2}$ cannot be greater than 1 . However, team 3 is inefficient because other teams in the PPS outperform it regarding these two game factors. In particular, the point $(6.4,4.8)$ shows that team 3 should score $6.46 \mathrm{~m}$ goals and $4.89 \mathrm{~m}$ goals in order to perform at the levels of the efficient teams (these are actually the targets for team 3 ). In other words, $\phi_{3}=1.60$ is the efficiency score of team 3 , which means that it should improve by $60 \%$ in these two game factors. The point $(6.4,4.8)$ is a benchmark for team 3 that results from a combination of team 1 and team 2 in which the participation of the former is $45 \%$ and that of latter is $55 \%$, i.e., $\lambda_{1}=0.45$ and $\lambda_{2}=0.55$ in model (2) (obviously, $\lambda_{3}=0$ ), so that

$$
\left(\begin{array}{l}
6.4 \\
4.8
\end{array}\right)=0.45 \times \mathrm{P}_{1}+0.55 \times \mathrm{P}_{2} \text {. }
$$

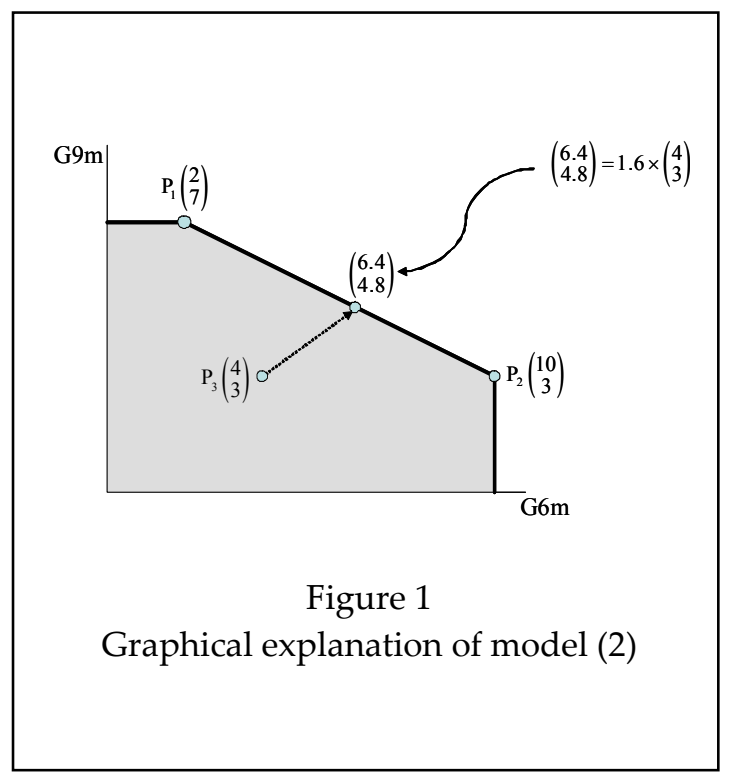

Finally, we use the cross-efficiency evaluation for the ranking of teams. The crossefficiencies of team 0 are the assessments of this team with the weights of the others. That is, if $\left(\omega_{1}^{\mathrm{d}}, \ldots, \omega_{8}^{\mathrm{d}}\right)$ are the weights of team $d$, obtained by solving (1) for that team, then the crossefficiency

$$
\mathrm{E}_{\mathrm{d}, 0}=\frac{1}{\omega_{1}^{\mathrm{d}} \times \mathrm{y}_{1,0}+\ldots+\omega_{8}^{\mathrm{d}} \times \mathrm{y}_{8,0}}
$$

is an evaluation of team 0 with the weights of team $\mathrm{d}$. The cross-efficiency score of team 0 is the average of such cross-efficiencies, i.e.,

$$
\overline{\mathrm{E}}_{0}=\frac{1}{24}\left(\mathrm{E}_{1,0}+\ldots+\mathrm{E}_{24,0}\right)
$$

The cross-efficiency scores provide thus a peer-appraisal in which each team is assessed with reference to the different patterns of game that the different teams have used in their DEA assessments, and also determine a full ranking of teams.

For those readers interested in details on the DEA models, their formulations and properties, see the textbook by Cooper et al. (2007). 


\section{Results}

The DEA model revealed that 9 out of the 24 teams participating in the championship were efficient. For each of them, Table 1 records the contributions to the efficiency of each game factor. These contributions, which are called "virtual weights", are the product of the absolute weights and the corresponding actual values, i.e., for team 0 these would be $\omega_{\mathrm{r}} \times \mathrm{y}_{\mathrm{r} 0}, \mathrm{r}=1, . ., 8$, where the $\omega^{\prime} \mathrm{s}$ are the weights provided by (1) when solved for that team. They are dimensionless and represent the percentages of contribution of each factor to the total efficiency $(100 \%)$, so they can be seen as the relative importance attached to each aspect of the game in the assessment of each team. This table also reports the number of times each of the efficient teams acted as referent in the assessment of the inefficient ones, which is determined as the number of times the corresponding $\lambda_{j}$ in model (2) is non-zero in the assessment of the different teams.

The benchmarking analysis provided by DEA is reported in Table 2. For each inefficient team, in this table we have its actual data (in the first row of each team) and the corresponding efficient targets (in the second row). The third row records the difference between the target and the actual data in relation to the actual data. Large values of these percentages may suggest the need of the team under assessment for improvement in the corresponding aspect of the game. Table 2 also reports which efficient teams compose the benchmark used in the assessments, together with their contributions as efficient referents in such benchmark, i.e., the $\lambda_{j}$ 's provided by model (2).

Table 3 records the cross-efficiencies (3) and the cross-efficiency scores (4). We note that in our analysis we used a variant of the standard cross-efficiency evaluation that assesses the teams by only using the weights of those that have been rated as efficient in the DEA self-evaluation (Ramón et al., 2011). Thus, the rows of this table correspond to each of the teams participating in the championship, and in each of them we have the evaluations of their game (the crossefficiencies) with the weights of each of the efficient teams (under the corresponding column). The last column of the table shows the crossefficiency scores and in brackets their corresponding rankings. We can see, for instance, that France ranks $1^{\text {st }}$ followed by Spain, Denmark and Slovakia, in this order. The teams in the rows of the table appear in order of the final classification of the world championship, so we can make comparisons between the two rankings.

Table 1

Efficient teams: Contributions to the efficiency and number of times acting as referent

\begin{tabular}{lcccccccccc}
\hline TEAM & G6m & Gwing & G9m & G7m & Gfastb & Gbt & Rec & Bloc & total & \#ref. \\
\hline FRA & $11.04 \%$ & $11.04 \%$ & $11.04 \%$ & $13.38 \%$ & $13.38 \%$ & $13.38 \%$ & $13.38 \%$ & $13.38 \%$ & $100.00 \%$ & 13 \\
DEN & $22.79 \%$ & $22.79 \%$ & $22.79 \%$ & $6.32 \%$ & $6.32 \%$ & $6.32 \%$ & $6.32 \%$ & $6.32 \%$ & $100.00 \%$ & 9 \\
SPA & $6.32 \%$ & $14.40 \%$ & $6.32 \%$ & $26.99 \%$ & $6.32 \%$ & $6.32 \%$ & $26.99 \%$ & $6.32 \%$ & $100.00 \%$ & 13 \\
CRO & $5.28 \%$ & $23.80 \%$ & $5.28 \%$ & $24.90 \%$ & $5.28 \%$ & $24.90 \%$ & $5.28 \%$ & $5.28 \%$ & $100.00 \%$ & 2 \\
ICE & $3.13 \%$ & $3.13 \%$ & $3.13 \%$ & $3.13 \%$ & $40.61 \%$ & $3.13 \%$ & $40.61 \%$ & $3.13 \%$ & $100.00 \%$ & 5 \\
HUN & $1.95 \%$ & $1.95 \%$ & $1.95 \%$ & $35.42 \%$ & $48.64 \%$ & $1.95 \%$ & $1.95 \%$ & $6.18 \%$ & $100.00 \%$ & 0 \\
NOR & $68.03 \%$ & $1.80 \%$ & $1.80 \%$ & $1.80 \%$ & $1.80 \%$ & $1.80 \%$ & $1.80 \%$ & $21.17 \%$ & $100.00 \%$ & 6 \\
KOR & $6.64 \%$ & $1.18 \%$ & $1.18 \%$ & $54.79 \%$ & $1.18 \%$ & $32.65 \%$ & $1.18 \%$ & $1.18 \%$ & $100.00 \%$ & 0 \\
SVK & $34.46 \%$ & $8.43 \%$ & $4.75 \%$ & $33.39 \%$ & $4.75 \%$ & $4.75 \%$ & $4.75 \%$ & $4.75 \%$ & $100.00 \%$ & 4 \\
\hline
\end{tabular}


Table 2

Benchmarking analysis: Actual data and efficient targets (inefficient teams)

\begin{tabular}{|c|c|c|c|c|c|c|c|c|c|}
\hline TEAM & G6m & Gwing & G9m & $\mathrm{G} 7 \mathrm{~m}$ & Gfastb & Gbt & $\operatorname{Rec}$ & Bloc & Benchmarks \\
\hline \multirow[t]{3}{*}{ SWE } & 2.44 & 2.50 & 3.30 & 1.58 & 3.29 & 3.31 & 3.50 & 2.90 & \multirow{3}{*}{$\begin{array}{l}\text { FRA }(28.56 \%), \operatorname{SPA}(24.23 \%), \\
\operatorname{DEN}(17.45 \%), \mathrm{CRO}(29.77 \%)\end{array}$} \\
\hline & 3.42 & 2.93 & 4.05 & 2.33 & 3.86 & 3.88 & 4.11 & 4.14 & \\
\hline & $40.37 \%$ & $17.35 \%$ & $22.83 \%$ & $47.87 \%$ & $17.35 \%$ & $17.35 \%$ & $17.35 \%$ & $42.90 \%$ & \\
\hline \multirow[t]{3}{*}{ POL } & 4.12 & 1.61 & 3.58 & 1.88 & 4.20 & 2.48 & 4.00 & 4.11 & \multirow{3}{*}{$\begin{array}{l}\text { FRA(48.94\%),SPA(6.91\%), } \\
\text { NOR(43.14\%),ICE(1.01\%) }\end{array}$} \\
\hline & 4.30 & 1.92 & 4.47 & 2.12 & 4.38 & 2.91 & 4.17 & 4.28 & \\
\hline & $4.22 \%$ & $18.83 \%$ & $24.74 \%$ & $12.66 \%$ & $4.22 \%$ & $17.15 \%$ & $4.22 \%$ & $4.22 \%$ & \\
\hline \multirow[t]{3}{*}{ SRB } & 2.50 & 3.13 & 4.27 & 2.03 & 2.24 & 2.79 & 2.11 & 3.11 & \multirow{3}{*}{$\begin{array}{l}\text { FRA(23.78\%),SPA(24.20\%), } \\
\operatorname{DEN}(45.72 \%), \mathrm{CRO}(6.31 \%)\end{array}$} \\
\hline & 3.57 & 3.44 & 4.69 & 2.23 & 4.09 & 3.07 & 3.99 & 4.11 & \\
\hline & $42.76 \%$ & $9.82 \%$ & $9.82 \%$ & $9.82 \%$ & $82.63 \%$ & $9.82 \%$ & $89.11 \%$ & $32.12 \%$ & \\
\hline \multirow[t]{3}{*}{ GER } & 3.88 & 2.63 & 4.71 & 1.46 & 2.86 & 2.73 & 4.00 & 3.33 & \multirow{3}{*}{$\begin{array}{l}\operatorname{FRA}(43.24 \%), \operatorname{SPA}(13.24 \%), \\
\operatorname{DEN}(24.19 \%), \operatorname{NOR}(19.33 \%)\end{array}$} \\
\hline & 3.94 & 2.67 & 4.78 & 2.14 & 4.32 & 3.12 & 4.06 & 4.29 & \\
\hline & $1.44 \%$ & $1.44 \%$ & $1.44 \%$ & $46.71 \%$ & $50.75 \%$ & $14.14 \%$ & $1.44 \%$ & $28.77 \%$ & \\
\hline \multirow[t]{3}{*}{ ARG } & 2.43 & 2.02 & 2.28 & 2.13 & 3.46 & 3.11 & 4.11 & 2.89 & \multirow{3}{*}{$\begin{array}{l}\text { FRA(47.24\%),SPA(43.70\%), } \\
\operatorname{DEN}(8.11 \%), \operatorname{ICE}(0.95 \%)\end{array}$} \\
\hline & 3.40 & 2.38 & 4.30 & 2.52 & 4.09 & 3.68 & 5.01 & 3.87 & \\
\hline & $40.29 \%$ & $18.24 \%$ & $88.04 \%$ & $18.24 \%$ & $18.24 \%$ & $18.24 \%$ & $21.86 \%$ & $34.05 \%$ & \\
\hline \multirow[t]{3}{*}{ EGY } & 2.60 & 3.18 & 2.30 & 1.72 & 2.48 & 1.68 & 3.29 & 2.71 & \multirow[t]{3}{*}{ SPA(36.05\%),DEN(63.95\%) } \\
\hline & 3.54 & 3.93 & 4.53 & 2.31 & 3.93 & 2.26 & 4.06 & 3.79 & \\
\hline & $35.74 \%$ & $23.61 \%$ & $96.99 \%$ & $34.06 \%$ & $58.75 \%$ & $34.30 \%$ & $23.61 \%$ & $39.53 \%$ & \\
\hline \multirow[t]{3}{*}{ ALG } & 2.55 & 1.50 & 2.62 & 0.57 & 2.10 & 1.98 & 3.29 & 2.14 & \multirow{3}{*}{$\begin{array}{l}\operatorname{FRA}(31.80 \%), \operatorname{SPA}(39.55 \%), \\
\operatorname{DEN}(3.69 \%), \operatorname{NOR}(21.87 \%), \\
\operatorname{SVK}(3.09 \%)\end{array}$} \\
\hline & 3.79 & 2.23 & 3.89 & 2.49 & 4.00 & 2.95 & 4.88 & 3.73 & \\
\hline & $48.53 \%$ & $48.53 \%$ & $48.53 \%$ & $336.20 \%$ & $90.39 \%$ & $48.53 \%$ & $48.53 \%$ & $74.15 \%$ & \\
\hline \multirow[t]{3}{*}{ JPN } & 2.22 & 2.15 & 1.76 & 0.86 & 4.71 & 3.62 & 3.00 & 1.29 & \multirow{3}{*}{$\begin{array}{l}\text { FRA }(63.88 \%), \operatorname{DEN}(13.90 \%), \\
\operatorname{ICE}(22.22 \%)\end{array}$} \\
\hline & 3.70 & 2.27 & 5.13 & 1.98 & 4.96 & 3.81 & 4.13 & 4.24 & \\
\hline & $66.69 \%$ & $5.21 \%$ & $191.49 \%$ & $129.84 \%$ & $5.21 \%$ & $5.21 \%$ & $37.79 \%$ & $229.42 \%$ & \\
\hline \multirow[t]{3}{*}{ AUT } & 3.72 & 1.26 & 4.52 & 1.56 & 4.99 & 2.04 & 3.29 & 4.29 & \multirow{3}{*}{$\begin{array}{l}\text { FRA(75.54\%),NOR(2.79\%), } \\
\operatorname{ICE}(21.67 \%)\end{array}$} \\
\hline & 3.73 & 1.87 & 5.09 & 2.01 & 4.99 & 4.11 & 4.31 & 4.29 & \\
\hline & $0.14 \%$ & $48.71 \%$ & $12.65 \%$ & $29.53 \%$ & $0.14 \%$ & $101.51 \%$ & $31.28 \%$ & $0.14 \%$ & \\
\hline \multirow[t]{3}{*}{ ROU } & 2.57 & 1.80 & 4.02 & 2.03 & 3.65 & 2.54 & 4.57 & 4.00 & \multirow[t]{3}{*}{ FRA(69.66\%),SPA(30.34\%) } \\
\hline & 3.49 & 2.09 & 4.67 & 2.39 & 4.31 & 4.26 & 4.84 & 4.23 & \\
\hline & $35.85 \%$ & $16.31 \%$ & $16.18 \%$ & $17.66 \%$ & $18.22 \%$ & $67.84 \%$ & $5.81 \%$ & $5.81 \%$ & \\
\hline \multirow[t]{3}{*}{ TUN } & 3.11 & 2.11 & 3.11 & 1.08 & 2.16 & 1.66 & 3.00 & 3.00 & FRA(17.98\%),SPA(17.10\%), \\
\hline & 4.15 & 2.82 & 4.33 & 2.18 & 4.13 & 2.21 & 4.00 & 4.00 & $\operatorname{DEN}(29.12 \%), \mathrm{NOR}(34.35 \%)$ \\
\hline & $33.45 \%$ & $33.45 \%$ & $39.30 \%$ & $102.06 \%$ & $91.19 \%$ & $33.45 \%$ & $33.45 \%$ & $33.45 \%$ & $\operatorname{SVK}(1.45 \%)$ \\
\hline BRA & 4.13 & 3.36 & 2.06 & 2.24 & 2.67 & 2.48 & 3.57 & 3.14 & SPA(16.38\%),DEN(38.52\%), \\
\hline & 4.18 & 3.41 & 3.46 & 2.27 & 4.09 & 2.83 & 3.91 & 3.49 & SVK(45.11\%) \\
\hline & $1.34 \%$ & $1.34 \%$ & $68.12 \%$ & $1.34 \%$ & $53.15 \%$ & $14.31 \%$ & $9.60 \%$ & $11.05 \%$ & \\
\hline $\mathrm{CHI}$ & 2.17 & 1.75 & 1.81 & 1.17 & 3.34 & 3.19 & 5.00 & 2.29 & FRA(37.89\%),SPA(62.11\%) \\
\hline & 3.26 & 2.25 & 3.81 & 2.75 & 3.85 & 3.51 & 5.50 & 3.53 & \\
\hline & $50.55 \%$ & $28.40 \%$ & $110.76 \%$ & $135.47 \%$ & $15.30 \%$ & $10.09 \%$ & $10.09 \%$ & $54.59 \%$ & \\
\hline BRN & 1.79 & 0.76 & 2.62 & 1.60 & 3.84 & 2.50 & 3.86 & 1.43 & FRA(40.11\%),SPA(22.70\%), \\
\hline & 3.50 & 1.93 & 4.26 & 2.24 & 4.87 & 3.17 & 4.89 & 3.40 & $\operatorname{ICE}(37.20 \%)$ \\
\hline & $96.04 \%$ & $155.65 \%$ & $62.75 \%$ & $40.57 \%$ & $26.82 \%$ & $26.82 \%$ & $26.82 \%$ & $138.33 \%$ & \\
\hline AUS & 1.72 & 0.87 & 1.54 & 1.61 & 1.33 & 1.52 & 2.86 & 1.14 & FRA(6.64\%),SPA(83.55\%), \\
\hline & 3.22 & 2.41 & 2.89 & 3.01 & 3.48 & 2.84 & 5.93 & 2.88 & NOR(0.99\%),SVK(8.81\%) \\
\hline & $87.42 \%$ & $176.56 \%$ & $87.42 \%$ & $87.42 \%$ & $161.13 \%$ & $87.42 \%$ & $107.65 \%$ & $152.38 \%$ & \\
\hline
\end{tabular}




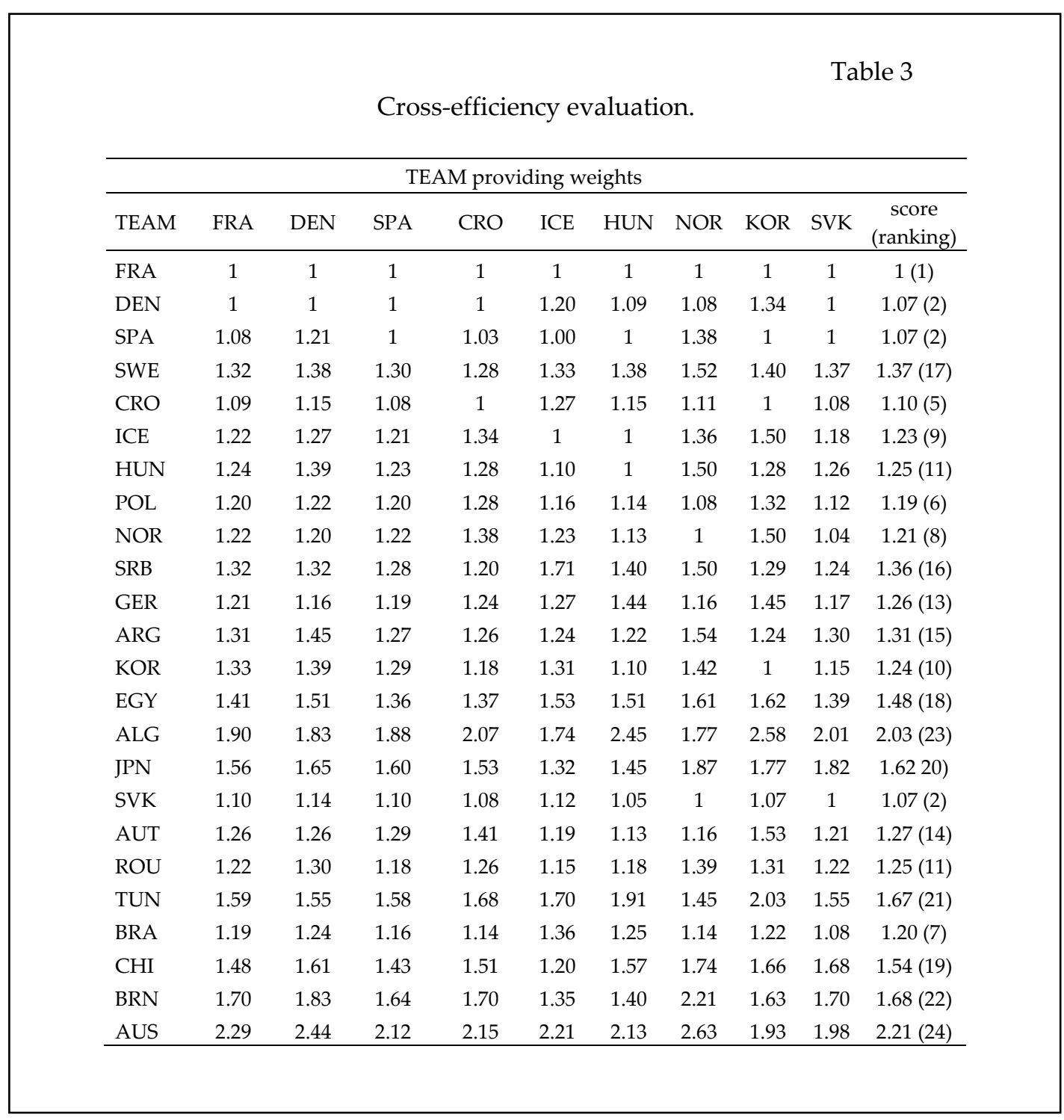

\section{Discussion}

On many occasions, tactics are validated on the basis of the achievement of victory, the winning team being rated as the best. However, we should not close the door to the analysis of other teams whose performance can serve as a model of efficiency for the game. For example, Table 1 shows that the 9 efficient teams achieved the efficiency with different patterns of game. We can see that France used a pattern of game in which all of the factors considered have the same importance. This shows a good performance of France in all of the aspects of the game. Denmark and Spain needed to put more weight in some of the game factors in order to be rated as efficient. Table 1 reveals that Denmark exploited to some extent its relative strength in G6m, Gwing and
G9m in the achievement of the efficiency (with a contribution to the efficiency of $22.79 \%$ ), while Spain did the same with Gwing $(14.40 \%)$, G7m and Rec (both with a contribution of $26.99 \%$ ). We can also see in this table that these three teams played an important role as benchmarks for the remaining players: they acted as referents in the assessments of 13, 9 and 13 inefficient teams, respectively.

In contrast, other teams like Iceland, Hungary, Norway and Korea achieved the efficiency with a very specialized pattern of game. See, in particular, the case of Norway, whose efficiency was due mainly to exploiting its good performance in G6m (with a contribution to the efficiency of $68.03 \%$ ), or that of Korea, which exploited to a large extent its behavior in G7m $(54.79 \%)$, and also in Gbt (32.65\%). We also note 
that neither Korea nor Hungary were referents for any of the inefficient teams.

Concerning the inefficient teams, Table 2 provides useful information for benchmarking purposes. For example, we can see that Germany is very similar to its benchmark, which is a virtual team determined mostly by France $(43.24 \%)$ and Denmark $(24.19 \%)$ (also by Spain and Norway with a less relevant role). Its actual data are very close to the targets provided in most of the aspects of the game. However, the DEA model identifies three areas for potential improvement: $\mathrm{G} 7 \mathrm{~m}$, where the actual data is 1.46 whereas the corresponding target is 2.14, which gives rise to a potential of improvement of $46.71 \%$; Gfastb, where it is needed a raise from the actual 2.86 to the target 4.32 which means an improvement of $50.75 \%$; and also in Bloc, where the percentage of improvement is $28.77 \%$. Poland, whose benchmark is mainly determined by France (48.94\%) and Norway (43.14\%), also shows a good performance in several of the factors of the game, while at the same time there is some room for improvement in other factors like G9m, Gwing, Gbt and G7m. That could be also the case of Austria or Brazil, but for these teams some important weaknesses are detected: in Gbt for Austria, with a percentage of improvement of $101.51 \%$, and in G9m (68.12\%) and in Gfastb $(53.15 \%)$ for Brazil. Finally, teams like Australia or Algeria exhibit a poor performance in practically all of the aspects of the game.

As for the cross-efficiency evaluation, we can firstly see in the row of France in Table 3 that all cross-efficiencies equal 1 , which means that France is rated with the maximum efficiency with the patterns of game that all the efficient teams used in their assessments. In other words, the cross-efficiency evaluation identifies France as an "all-round" performer, because it is rated as efficient with a wide variety of models of game. As a result, it ranks 1st: its cross-efficiency score 1 is the largest in the last column of this table. Denmark and Spain are also rated as efficient with the weights of some other teams. France, Spain, Croatia and Slovakia assess Denmark as efficient (aside from Denmark itself), while Spain is evaluated as efficient by Hungary, Korea and Slovakia (apart from by Spain itself). However, other countries give these two teams some poor assessments: Korea and Iceland give Denmark the scores 1.34 and 1.20, respectively, perhaps due to fact that they both use a very specialized pattern of game, while Norway and Denmark make a similar evaluation of Spain. In the case of Norway, the reason behind the low score (1.38) can also be the specialization of the Norway's game model above mentioned, but in that of Denmark it seems that this team is penalizing Spain (1.21) in forcing it to put more weight on G9m and G6m, which are weaker points of Spain's game. Finally, we can see that all of the teams give good ratings to Slovakia, and this is why it eventually ranks $2^{\text {nd }}$, together with Denmark and Spain.

The cross-efficiency evaluation has made it possible to discriminate between the teams initially rated as efficient in the DEA selfevaluation. Note that the cross-efficiency score of the teams in the first five positions of the ranking (Croatia is the country ranking $5^{\text {th }}$ ) are substantially larger than those of the other four, which are the efficient teams that have used the most unbalanced patterns of game in their assessment (Norway, Iceland, Korea and Hungary). Perhaps as a result, some inefficient teams like Poland and Brazil rank before these four efficient teams.

The comparison between the ranking concerning game performance provided by the cross-efficiency evaluation and the final classification of the championship allows us to conclude that France, which is the world champion, is an "all-round" performer, now in the sense that it is the best regarding both game performance and competitive performance. Denmark and Spain, which were $2^{\text {nd }}$ and $3^{\text {rd }}$ in the tournament, respectively, keep their positions in our analysis, so they are also good performers. However, we can also see differences between both rankings. Among them, we highlight the cases of Slovakia and Brazil on one hand and that of Sweden on the other. While in the ranking provided by the cross-efficiency evaluation Slovakia and Brazil gain $15^{\text {th }}$ and $14^{\text {th }}$ positions, respectively, with respect to the final classification in the world championship, Sweden would lose $13^{\text {th }}$. Thus, we can conclude that Brazil and Slovakia did not exploit sufficiently in competition the good performance of their game, whereas Sweden showed itself as a strong competitor. It should be noted that Brazil and 
Slovakia had poor results in the first round of the championship, when they had to play against teams with more potential. In contrast, we would like to stress the fact that Sweden hosted the Championship, so the emotional factor or the home advantage may have given them some edge, and this might explain their good results in competition when those concerned with the performance of the game are not particularly good.

\section{Conclusions}

This paper illustrates the use of DEA and cross-efficiency evaluation for the assessment of game performance of sports teams. In particular, this study could be useful for coaches of handball teams to improve individual and collective tactics in competition. There are other issues that can also be addressed with these methodologies. For example, although we leave out of consideration such issues like team budgets, etc., the DEA models can incorporate that type of inputs in their formulations, if available, and develop measures of team efficiency. This could also be considered in assessments of performance at the level of players. Likewise, these assessments can be made from a different perspective like that concerned with organizational performance. In general, the results obtained have shown that DEA and crossefficiency evaluation are useful support tools for coaching and managing sports teams.

\section{References}

Alp I. Performance Evaluation of Goalkeepers of the World Cup. J Sports Sci, 2006; 19(2): 119-125

Anderson TR, Sharp GP. A new measure of football batters using DEA. Ann Oper Res, 1997; 73: 141-155

Barros CP, Assaf A, Sá-Earp F. Brazilian Football League Technical Efficiency: A Simar and Wilson Approach. JSE, 2010; 11(6): 641-651

Boscá JE, Liern V, Martínez A, Sala R. Increasing offensive or defensive efficiency? An analysis of Italian and Spanish football. Omega, 2009; 37: 63-78

Charnes A, Cooper WW, Rhodes E. Measuring the efficiency of decision making units. EJOR, 1978; 2: 429-444

Chen WC, Johnson AL. The dynamics of performance space of Major League Baseball pitchers 1871-2006. Ann Oper Res, 2010; 181(1): 287-302

Cooper WW, Ramón N, Ruiz JL, Sirvent I. Avoiding large differences in weights in cross-efficiency evaluations: application to the ranking of basketball players. JCC, 2011; 4(2): 197-215

Cooper WW, Ruiz JL, Sirvent I. Selecting non-zero weights to evaluate effectiveness of basketball players with DEA. EJOR, 2009; 195 (2): 563-574

Cooper WW, Ruiz JL, Sirvent I. Choices and uses of DEA Weights. In Handbook On Data Envelopment Analysis (William W. Cooper, Lawrence W. Seiford and Joe Zhu, Eds.) Springer, 2011: 93-126

Cooper WW, Seiford LM, Tone K. Data Envelopment Analysis: A Comprehensive Text with Models, Applications, References and DEA-Solver Software, 2nd ed. Springer Science \& Business Publishers, New York; 2007

Dawson P, Dobson S, Gerrard B. Estimating coaching efficiency in professional team sports: Evidence from English association football. Scottish Journal of Political Economy, 2000; 47 (4): 399-419

Doyle JR, Green RH. Strategic choice and data envelopment analysis: Comparing computers across many dimensions. JIT, 1994; 9: 61-69

Einolf KW. Is Winning Everything?: A Data Envelopment Analysis of Major League Baseball and the National Football League. JSE, 2004; 5(2): 127-151

Espitia-Escuer M, García-Cebrián LI. Measuring the Efficiency of Spanish First-Division Soccer Teams. JSE, 2004; 5(4): 329-346

Fizel JL, D’Itri MP. Firing and hiring of managers: Does efficiency matter? JOM, 1999; 25: 567-585 
Fried HO, Lambrinos J, Tyner J. Evaluating the performance of professional golfers on the PGA, LPGA an SPGA tours. EJOR, 2004; 154: 548-561

Fried HO, Tauer LW. The impact of age on the ability to perform under pressure: golfers on the PGA tour. J Prod Anal, 2011; 35(1): 75-84

García-Sánchez IM. Efficiency and effectiveness of Spanish football teams: a three-stage-DEA approach. Cent Eur J Oper Res, 2007; 15 (1): 21-45

González-Gómez F, Picazo-Tadeo AJ. Can We Be Satisfied With Our Football Team? Evidence from Spanish Professional Football. JSE, 2010; 11(4): 418-442

Gruic I, Dinko V, Dragan M. Performance indicators of teams at the 2003 men's world handball championship in Portugal. Kinesiology, 2006; 38(2): 164-175

Haas D, Kocher MG, Sutter M. Measuring efficiency of German Football Teams by Data Envelopmen Analysis. Cent Eur J Oper Res, 2001; 12: 251-268

Haas DJ. Technical Efficiency in the Major League Soccer. JSE, 2003; 4(3): 203-215

Hraste M, Dizdar D, Trninic V. Experts Opinion about System of the Performance Evaluation Criteria Weighted per Positons in the Water Polo Game. Coll Antr, 2008; 32: 851-861

Lozano S, Villa G, Guerrero F, Cortés P. Measuring the performance of nations at the Summer Olympics using data envelopment analysis. JORS, 2002; 53: 501-511

Ramón N, Ruiz JL, Sirvent I. Reducing differences between profiles of weights: A "peer-restricted" crossefficiency evaluation. Omega, 2011; 39(6): 634-641

Ramón N, Ruiz JL, Sirvent I. Common sets of weights as summaries of DEA profiles of weights: with an application to the ranking of professional tennis players. Expert Systems with Applications, 2012; 39: 4882-4889

Ruiz JL, Pastor D, Pastor JT. Assessing professional tennis players using data envelopment analysis (DEA), JSE, 2011; 27

Sexton TR, Lewis HF. Two-stage DEA: An application to major league baseball. J Prod Anal, 2003; 19: 227-249

Sexton TR, Silkman RH, Hogan AJ. Data envelopment analysis: Critique and extensions, in Measuring efficiency: An assessment of data envelopment analysis, Silkman, R.H. (editor), Jossey-Bass, San Francisco, 1986; 73-105

Soares de Mello JC, Angulo-Meza L, Branco da Silva BP. A ranking for the Olympic Games with unitary input DEA models. IMA J Manag Math, 2009; 20: 201-211

Sueyoshi T, Ohnishi K, Kinase Y. A Benchmark Approach for Baseball Evaluation. EJOR, 1999; 115: 429-448

Swalgin K. The basketball evaluation system: a computerized factor weighted model with measures of validity. Kinesiology, 1998: 30, 31-37

Tenga A, Holme I, Ronglan LT, Bahr R. Effect of playing tactics on achieving score-box possessions in a random series of team possessions from Norwegian professional soccer matches. J Sports Sci, 2010a; 28: $245-255$

Tenga A, Holme I, Ronglan LT, Bahr R. Effect of playing tactics on goal scoring in Norwegian professional soccer. J Sports Sci, 2010b; 28: 237-244

Tenga A, Ronglan LT, Bahr R. Measuring the effectiveness of offensive match-play in professional soccer. Eur J Sports Sci, 2010c; 10(4): 269-277

Trninic S, Dizdar D. System of the Performance Evaluation Criteria Weighted per Positions in the Basketball Game. Coll Antr, 2000; 24: 217-234

Trninic S, Dizdar D, Dezman B. Pragmatic Validity of the Combined Model of Expert System for Assessment and Analysis of the Actual Quality Overall Structure of Basketball Players. Coll Antr, 2002; 26: 199210

Ueda T, Amatatsu H. Determination of bounds in DEA assurance region method - its application to evaluation of baseball players and chemical companies. J Oper Res Soc Jpn, 2009; 4: 453-467

Volz B. Minority Status and Managerial Survival in Major League Baseball. JSE, 2009; 10(5): 522-542 
Wu J, Zhou Z, Liang L. Measuring the Performance of Nations at Beijing Summer Olympics Using IntegerValued DEA Model, JSE, 2010; 11(5); 549-566

Zhang D, Li X, Meng W, Liu W. Measuring the performance of nations at the Olympic Games using DEA models with different preferences. Cent Eur J Oper Res Soc, 2009; 60: 983-990

\section{Corresponding Author:}

Óscar Gutiérrez

Center of Research in Sport

University Miguel Hernández of Elche.

Avd. De la Universidad s/n, 03202, Elche, Spain.

Phone: (+34) 965222454

E-mail: ogutierrez@umh.es 